\title{
The Role of Methyl Groups in the Early Stage of Thermal Polymerization of Polycyclic Aromatic Hydrocarbons Revealed by Molecular Imaging
}

Pengcheng Chen, Shadi Fatayer, Bruno Schuler, Jordan N. Metz, Leo Gross, Nan Yao,* and Yunlong Zhang*

Cite This: Energy Fuels 2021, 35, 2224-2233

Read Online

ACCESS | Lill Metrics \& More | 国 Article Recommendations | st Supporting Information

ABSTRACT: The initial thermal reactions of aromatic hydrocarbons are relevant to many industrial applications. However, tracking the growing number of heavy polycyclic aromatic hydrocarbon (PAH) products is extremely challenging because many reactions are unfolding in parallel from a mixture of molecules. Herein, we studied the reactions of 2,7-dimethylpyrene (DMPY) to decipher the roles of methyl substituents during mild thermal treatment. We found that the presence of methyl substituents is key for reducing the thermal severity required to initiate chemical reactions in natural molecular mixtures. A complex mixture of thermal products including monomers, dimers, and trimers was characterized by NMR, mass spectrometry, and noncontact atomic force microscopy (nc-AFM). A wide range of structural transformations including methyl transfer and polymerization reactions were identified. A detailed mechanistic understanding on the roles of $\mathrm{H}$ radicals during the polymerization of polycyclic aromatic hydrocarbons was obtained.

\section{INTRODUCTION}

Aromatic hydrocarbons undergo numerous reactions under thermal conditions. Under severe thermal situations, such as those at pyrolytic temperatures above $1000{ }^{\circ} \mathrm{C}$ during flame combustion, laser ablation or chemical vapor deposition (CVD), hydrocarbons undergo molecular weight growth and transform into various carbonaceous materials, such as buckminsterfullerene $\left(\mathrm{C}_{60}\right)$, carbon nanotubes, graphenes, graphite, and coke. ${ }^{1-5}$ The formation of aromatic rings and their polymerization and condensation have been extensively studied, and multiple complementary formation mechanisms, including the Diels-Alder (DA) reaction and hydrocarbonabstraction-acetylene-addition (HACA) mechanisms have been proposed. ${ }^{6-8}$ In particular, the cyclopentadienyl $\left(\mathrm{C}_{5}\right)$ species is believed to be an important intermediate for the formation of first aromatic rings.

Aromatic hydrocarbons also react under relatively mild thermal conditions. The early stage of mild thermal reactions, reflected by the intrinsic reactivity of aromatic hydrocarbons, has significant implications in numerous industrial processes, such as fouling, thermal cracking, coking, and upgrading of heavy oils. ${ }^{10-13}$ For example, it is known that petroleum and other natural hydrocarbon resources undergo reactions at around $350-400^{\circ} \mathrm{C},{ }^{14-20}$ which is associated with the onset of thermal cracking because many covalent bonds (e.g., $\mathrm{C}-\mathrm{H}$ and $\mathrm{C}-\mathrm{C}$ bonds) break on reaching this temperature range. The free radicals produced via homolytic cleavage of covalent bonds couple with other molecules to form ever-larger molecules with increasing molecular weight up to and including coke. ${ }^{21,22}$ However, the detailed mechanism is still unclear and is the focus of this study.
In a previous AFM study on petroleum pitch $\mathrm{M}-50,{ }^{23}$ methyl substituents on PAHs were identified as a key common feature in most structures, consistent with extensive studies on this material over half a century. ${ }^{24-30}$ However, questions remain on how petroleum pitches are thermally converted and transformed into carbon materials under relatively mild thermal conditions. ${ }^{31}$ Important insights on the polymerization of PAHs have been obtained by studying various pitches made from model PAHs (pyrene, naphthalene, phenanthrene, etc.). ${ }^{32-34}$ However, most of the existing studies on model PAHs employed catalysts $\left(\mathrm{AlCl}_{3}\right.$ or $\left.\mathrm{HF}\right)$, and hence different mechanisms are expected. ${ }^{32,33}$ In addition, surface-assisted polymerization and cyclodehydrogenation of tailored $\mathrm{PAH}$ precursors have been studied extensively, ${ }^{35-38}$ and the role of surfaces has been shown to be important. In this work, we compare the thermal reactions of pyrene with 2,7-dimethylpyrene (DMPY) without catalysts, which is identical to the thermal condition (hours at $400{ }^{\circ} \mathrm{C}$ ) employed in the thermal conversion of M-50 pitch. The products are characterized with NMR, MS, and CO-tip noncontact AFM, which has been successfully applied to M-50 pitch, ${ }^{23}$ various petroleum mixtures, ${ }^{19,39,40}$ and model PAH compounds. ${ }^{41-44}$

Received: November 27, 2020

Revised: December 23, 2020

Published: January 12, 2021 

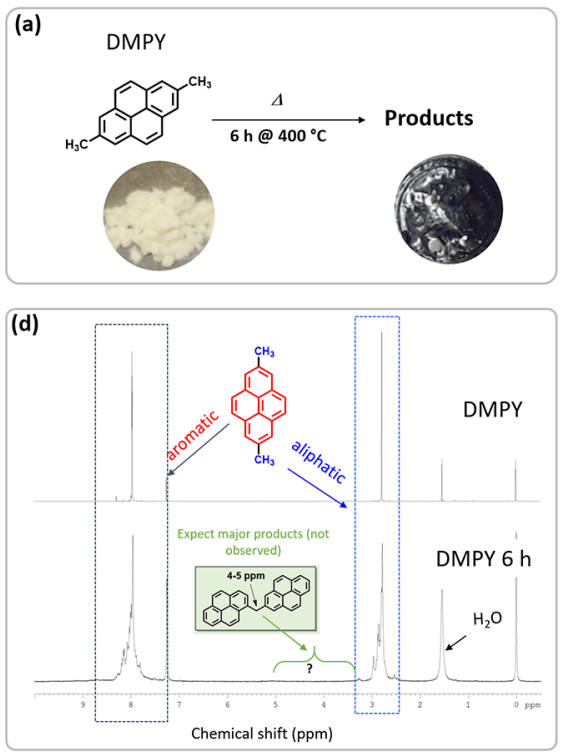
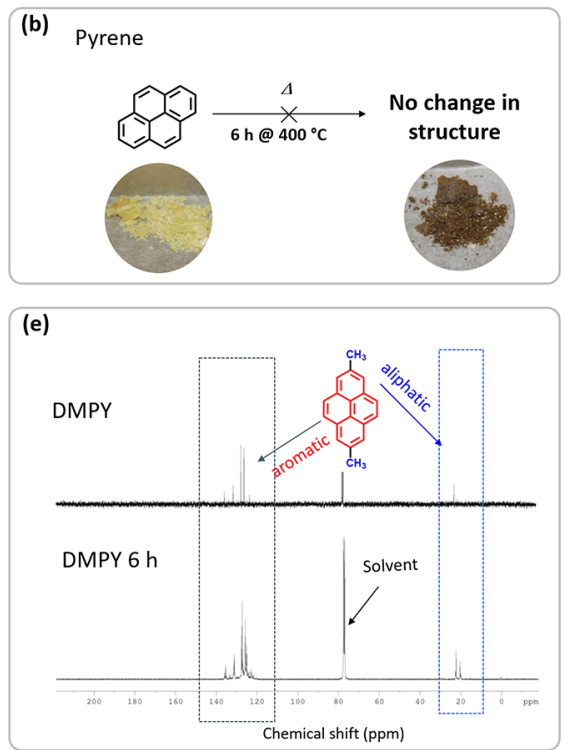
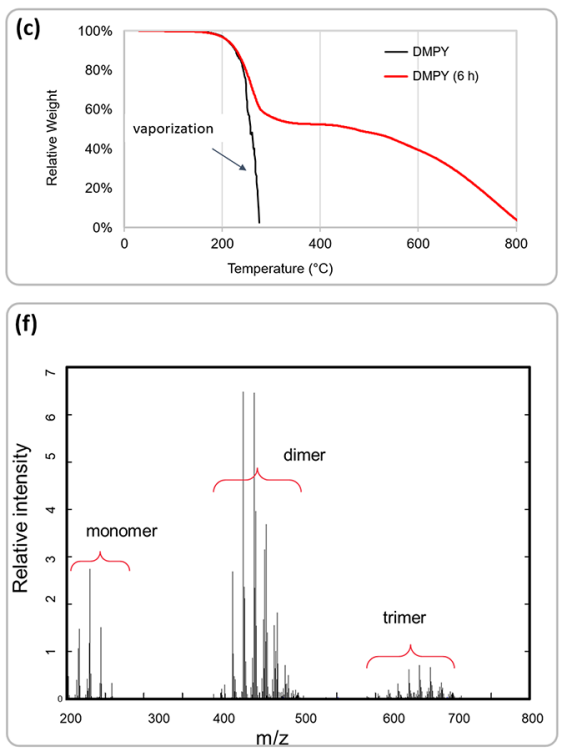

Figure 1. Studying the effect of methyl groups on the different thermal reactivities of pyrene and 2,7-dimethylpyrene (DMPY). (a) Pitch materials were obtained from DMPY after thermal treatment at $400{ }^{\circ} \mathrm{C}$ for $6 \mathrm{~h}$, and (b) no conversion of pyrene was achieved at the same thermal treatment based on NMR and GC-MS analysis (the color change is likely caused by phase change or minor impurities). (c) Thermogravimetric analysis (TGA) showed that DMPY pitch products are comprised of both low and high molecular weight molecules. Comparison of DMPY with pitch products after thermal treatments at $400{ }^{\circ} \mathrm{C}$ for $6 \mathrm{~h}$ with ${ }^{1} \mathrm{H}$ NMR (d) and ${ }^{13} \mathrm{C}$ NMR (e) spectra. Assignments of aliphatic (in blue) and aromatic (in red) structural moieties are related to their expected regions in NMR spectra. The distinctive absorption peaks by the $\mathrm{CH}_{2}$ linker expected at 3.5-5 ppm (in green) were not detected in ${ }^{1} \mathrm{H}$ NMR spectra. (f) FT-ICR MS with APPI ionization of DMPY thermal products (400 ${ }^{\circ} \mathrm{C}$ for $6 \mathrm{~h}$ ) showed peak clusters including monomers, dimers, and trimers.

\section{MATERIALS AND METHODS}

2.1. Materials. Pyrene was obtained from Sigma-Aldrich Co. 2,7Dimethylpyrene (DMPY) was custom synthesized (AbovChem LLC., San Diego, CA) by $n$-BuLi treatment of 2,7-dibromopyrene and then alkylation with methyl iodide in anhydrous tetrahydrofuran. The yield of the isolated product was around $73 \%$. The structures and purities of pyrene (97\%) and DMPY (96\%) were confirmed by NMR and GCMS (Figure 1, Supporting Information, SI, Figures S1-S6). DMPY was designed due to its symmetric structure, which facilitates both its synthesis and characterization.

2.2. Methods. 2.2.1. Thermal Treatment in Batch Microreactors. Stainless steel sealed tube microreactors (Swagelok) with a volume of approximately $15 \mathrm{~mL}$ and working pressures up to 24 $\mathrm{MPa}(3500 \mathrm{psig})$ and temperatures up to $450{ }^{\circ} \mathrm{C}$ were employed for the heat treatment. In a typical experiment, approximately $0.5 \mathrm{~g}$ of sample was loaded into the reactor chamber and sealed at ambient conditions. The reactor was submerged into a fluidized sand bath, which was prestabilized at the desired temperatures. After heating for different periods of time, the reactor was removed from the sand bath and cooled to room temperature overnight before the vessel was opened in a chemical fume hood. The weight of the vessel and the material was measured and the weight loss due to potential gaseous products was negligible $(<0.5 \%)$.

2.2.2. nc-AFM. nc-AFM was carried out with a low temperature (LT), ultrahigh vacuum (UHV) scanning tunneling microscope (STM) and atomic force microscope (AFM) system (CreaTec Fischer \& Co., GmbH, Germany) operated at $4.7 \mathrm{~K}$ and ultrahigh vacuum $\left(\sim 10^{-10} \mathrm{mbar}\right)$ with a Nanonis controller. ${ }^{39-41,43,45}$ A qPlus sensor ${ }^{46}$ with a PtIr tip was sharpened with focused ion beam milling and functionalized with a single carbon monoxide molecule. ${ }^{43} \mathrm{~A}$ $\mathrm{Cu}(111)$ single crystal was cleaned by sputtering with $\mathrm{Ar}^{+}$and annealing. Molecules were introduced by the resistive heating method using a silicon wafer, similar to that previously described. ${ }^{19,39-41,47-49}$ The molecules were evaporated onto the $\mathrm{Cu}$ sample at a sample temperature of about $T=10 \mathrm{~K}$ and investigated at $T=5 \mathrm{~K}$. Therefore, thermally activated on-surface reactions can be excluded. AFM images were obtained at constant height in the frequency- modulation mode, ${ }^{50}$ with quality factor $Q \approx 20000$, stiffness $k \approx 1800$ $\mathrm{N} / \mathrm{m}$, resonance frequency $f_{0} \approx 30 \mathrm{kHz}$, and oscillation amplitude of $A=100 \mathrm{pm}$.

2.2.3. NMR. ${ }^{1} \mathrm{H}$ and ${ }^{13} \mathrm{C}$ NMR spectra were obtained with a 400 $\mathrm{MHz}\left(100 \mathrm{MHz}\right.$ for $\left.{ }^{13} \mathrm{C}\right)$ Bruker Ascend spectrometer with $\mathrm{CDCl}_{3}$ as the solvent and with $0.003 \%$ TMS (tetramethylsilane) as the reference. Data was processed with TopSpin 4.0.6 software.

2.2.4. Mass Spectrometry. Fourier transform ion cyclotron resonance mass spectrometry (FICR MS) was conducted on a Bruker $15 \mathrm{~T}$ solariX FT-ICR MS (Bruker Daltonics Inc., Billerica, MA, USA). A solution in toluene with a concentration of 25-100 ppm was prepared and injected into an atmospheric pressure photoionization (APPI) source. Nitrogen was used as both the nebulizing and the drying gas. Data acquisition was set between $\mathrm{m} / z$ 300 and 3000 with an accumulation time between 40 and $60 \mathrm{~ms}$. Data analysis was performed with the Bruker data analysis (DA) software and calibrated with an internal homologous mass series.

2.2.5. Thermogravimetric Analysis (TGA). A PerkinElmer Pyris 1 TGA was utilized for the thermogravimetric analysis. Approximately $10 \mathrm{mg}$ of sample was loaded into a staged platinum pan, and the temperature was scanned from 30 to $950{ }^{\circ} \mathrm{C}$ with a ramp rate of 3 ${ }^{\circ} \mathrm{C} / \mathrm{min}$ under a high purity dried nitrogen flow $(60 \mathrm{~mL} / \mathrm{min})$. Prior to thermal scanning the sample was allowed to equilibrate in the staged pan under nitrogen for $30 \mathrm{~min}$ to ensure an established inert environment.

\section{RESULTS AND DISCUSSION}

3.1. The Role of Methyl in PAH Polymerization. The role of methyl (and alkyl) substituents during thermal polymerization of PAHs was investigated by comparing 2,7dimethylpyrene (DMPY) with pyrene (Figure 1). Both compounds were subject to the same thermal severity $(6 \mathrm{~h}$ at $400{ }^{\circ} \mathrm{C}$ ) in batch microreactors, and significantly different reactivities were observed. Despite a minor change in color of pyrene from light yellow to brown after thermal treatment, shown in Figure 1b, no significant compositional or structural 
Scheme 1. Known Reaction Mechanism and Anticipated Major Product Molecules from Thermal Treatment of DMPY ${ }^{a}$

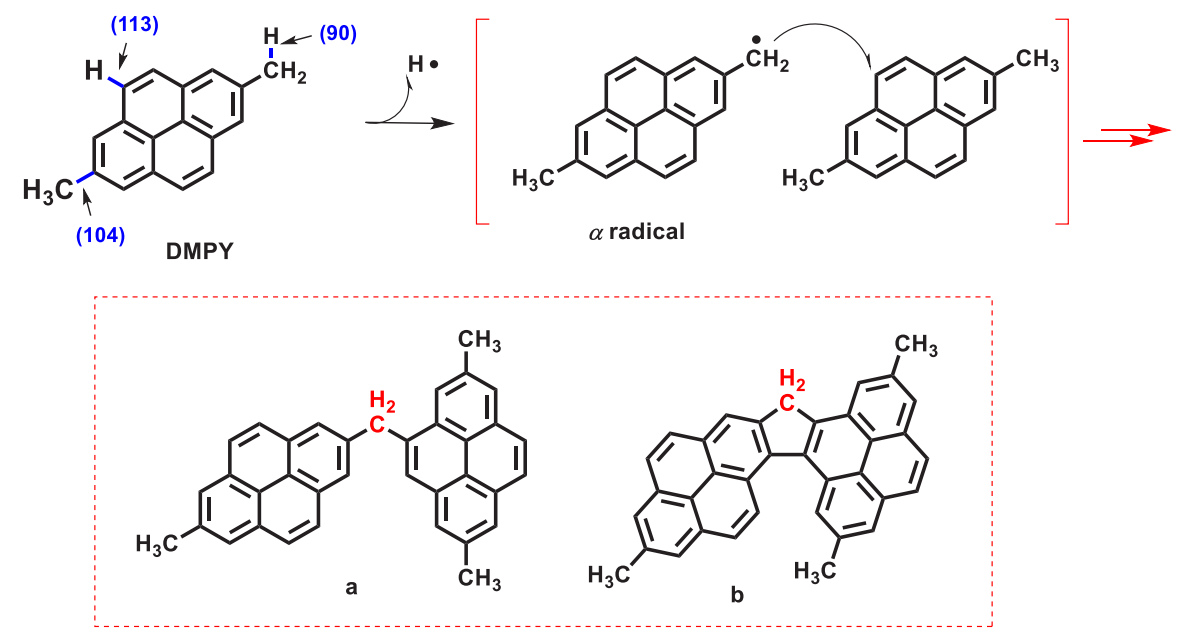

${ }^{a}$ Exemplar molecules are indicated by a and b. Bond dissociation energies (BDE) for indicated bonds (in blue) are shown in $\mathrm{kcal} / \mathrm{mol}$ in parentheses. The highlighted $\mathrm{CH}_{2}$ linker moieties (red) in the anticipated products are expected to have diagnostic chemical shifts at 4-5 ppm in NMR.

changes were detected by NMR and GC-MS data (Supporting Information, Figures S1-S5). Hence, the color change was likely caused by phase changes or minor impurities from heating. This lack of conversion by pyrene was further supported by additional heating (i.e., increasing the reaction temperature to $450{ }^{\circ} \mathrm{C}$ or by extending the heating time), and again no significant products were formed. This result for pyrene is consistent with earlier studies in which a thermal severity of heating at $500{ }^{\circ} \mathrm{C}$ for $50 \mathrm{~h}$ was required for a significant conversion of naphthalene, ${ }^{34,51}$ which is expected to have similar reactivity to pyrene. Previous studies also showed that pitches were only made from pyrene in the presence of catalysts $\left(\mathrm{AlCl}_{3}\right.$ or $\left.\mathrm{HF}\right)$ at $350-400{ }^{\circ} \mathrm{C} .{ }^{32,33,52-54}$ Hence, the lack of significant conversion of pyrene under the thermal treatment employed in this study is consistent with previous studies.

In contrast, thermal treatment of DMPY produced a black pitch material under the same conditions (Figure 1a). The significant conversion of DMPY is indicated by a mass residue of $40-50 \%$ remaining at $300-500{ }^{\circ} \mathrm{C}$, shown using TGA (Figure 1c). The significant amount of residue at this temperature range indicates molecular weight growth from thermal reactions, because DMPY or similar organic molecules are unlikely to have residue at above $260{ }^{\circ} \mathrm{C}$ due to evaporation or sublimation in TGA. The growth of molecular weight is also evident from the change of solubility in organic solvents. Materials insoluble in organic solvents including toluene, dichloromethylene (DCM), and chloroform were formed after thermal treatments, and they increased with higher thermal severities (longer time or higher temperatures). For example, although DMPY is fully soluble in DCM, 15\% of mass was insoluble after $3 \mathrm{~h}$ treatment, and $\sim 65 \%$ of mass was insoluble after $6 \mathrm{~h}$ treatment in the same solvent. The insoluble materials were removed by filtration in the following NMR and MS analyses, except in nc-AFM imaging.

NMR analysis of the thermal transformation of DMPY showed only a significant peak broadening, without new peaks observed for the products. For example, the ${ }^{1} \mathrm{H}$ NMR spectra in Figure 1d showed that the chemical shifts of methyl groups (at $\sim 2.5-3.5 \mathrm{ppm}$ ) and PAHs ( 7.5-8.5 ppm) remained unchanged, except for peak broadening in the thermalized products. ${ }^{13} \mathrm{C}$ NMR spectra also showed that very few new carbon peaks emerged in the products (Figure 1e). The lack of new absorptions in the NMR spectra of products is unexpected, considering the significant structural transformation and molecular weight growth based on TGA data and change in solubility. Especially, distinctive adsorptions at 4-5 ppm are expected in ${ }^{1} \mathrm{H}$ NMR for structures containing methylene $\left(\mathrm{CH}_{2}\right)$ linkers, or 3-4 ppm for ethylene $\left(\mathrm{CH}_{2} \mathrm{CH}_{2}\right)$ linkers. These products are expected to be predominant based on the widely accepted mechanisms shown in Scheme 1 via the formation of a stabilized $\alpha$ radical by thermal cracking of the weakest $\mathrm{C}(\alpha)-\mathrm{H}$ bond in DMPY and subsequent alkylation reactions with PAHs. ${ }^{42}$ The lack of NMR peaks associated with the $\mathrm{CH}_{2}$ linker moieties suggests that these anticipated structures are not dominant, raising questions about the predominance of the reaction mechanism shown in Scheme 1.

Mass spectrometry shown in Figure if and Figures S2-S6 revealed a mixture of molecules in products. APPI FT-ICR MS data showed that the thermal treatment of DMPY at $400{ }^{\circ} \mathrm{C}$ for $6 \mathrm{~h}$ produced a mixture of monomers $(200-250 \mathrm{Da})$, dimers $(400-500 \mathrm{Da})$, and trimers $(600-700 \mathrm{Da})$. The observation of higher molecular weight species confirmed the TGA data on the formation of condensed molecules. The formation of dimers and trimers could be in principle consistent with the mechanism of condensation shown in Scheme 1. However, the structures of product molecules remain unknown. To characterize these product structures, we resorted to the noncontact AFM technique, which has recently been used to characterize structures of a wide range of organic molecules ${ }^{41,42}$ and molecular mixtures. ${ }^{19,39,40,47,55}$

3.2. Structure Characterization of Thermal Products from DMPY with nc-AFM. Structures of products from thermal treatment of DMPY were imaged with nc-AFM by depositing the molecules directly onto the cryo stage at $10 \mathrm{~K}$. Different areas of the sample were investigated, and a total of about 30 images shown in Figure 2 were recorded comprising approximately 70 molecules (individual molecules labeled by numbers). The polyaromatic rings and their aliphatic substituents can be identified in the nc-AFM images, facilitated by deduction from the structure of the reactant DMPY. Carbon monoxide (CO) coabsorbed for tip functionaliza- 


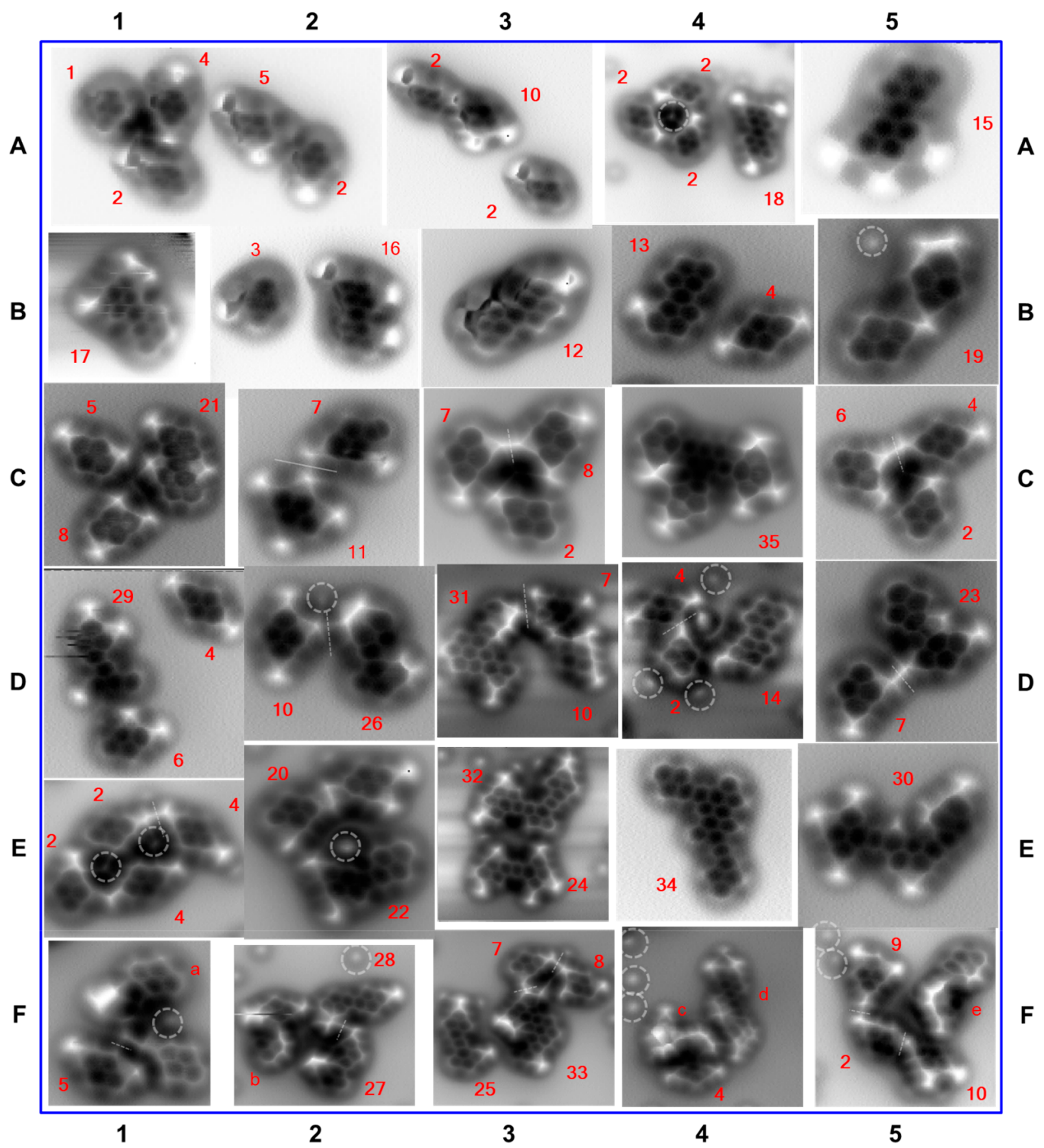

Figure 2. Constant-height CO-tip nc-AFM images of the thermalized products from DMPY deposited on $\mathrm{Cu}(111)$. Dashed circles indicate carbon monoxide (CO) molecules. Dashed lines indicate separate molecules rather than covalently bonded structures. Distinctive molecules are labeled by numbers and their assigned chemical structures are shown in Scheme 2. Molecules labeled by lower case letters (a-e) could not be assigned unambiguously to chemical structures.

tion, ${ }^{56}$ unrelated to the thermal product species, is indicated by dashed circles. Occasionally a few molecules were clustered together, or close to each other, sometimes with a $\mathrm{CO}$ absorbed between the molecules (panels A4 and E2 in Figure 2). ${ }^{57,58}$ The AFM data show that many fused products are formed by the thermal treatment of DMPY. Many isomers of DMPY are observed as well, including a few unreacted DMPY, which is expected for the incomplete conversion of DMPY chosen on purpose to understand the initial reactions.

It is important to identify the linkers between the pyrene moieties, because the predominant structural manifolds predicted by Scheme 1 contain a $\mathrm{CH}_{2}$ linker between aromatic units. However, clustered molecules complicate the assignment, as they sometimes feature apparent bonds between distinct molecules. It is known that using AFM with $\mathrm{CO}$ functionalized tips, features that look similar to covalent bonds (apparent bonds) can be observed even in the absence of bonds. ${ }^{59-61}$ This is explained by the flexibility of the CO tip $^{45,62}$ that can lead to apparent bonds along the ridges of potential energy wells, even in the absence of bonds at the respective positions. In most images, clustered individual molecules can be discerned by the large separation between them (such as in panels A1, A4, C2, D2, F1, and F2 in Figure $2)$, and hence they were assigned as different molecules 
Scheme 2. Product Molecules from Thermal Treatment of DMPY Characterized by AFM ${ }^{a}$

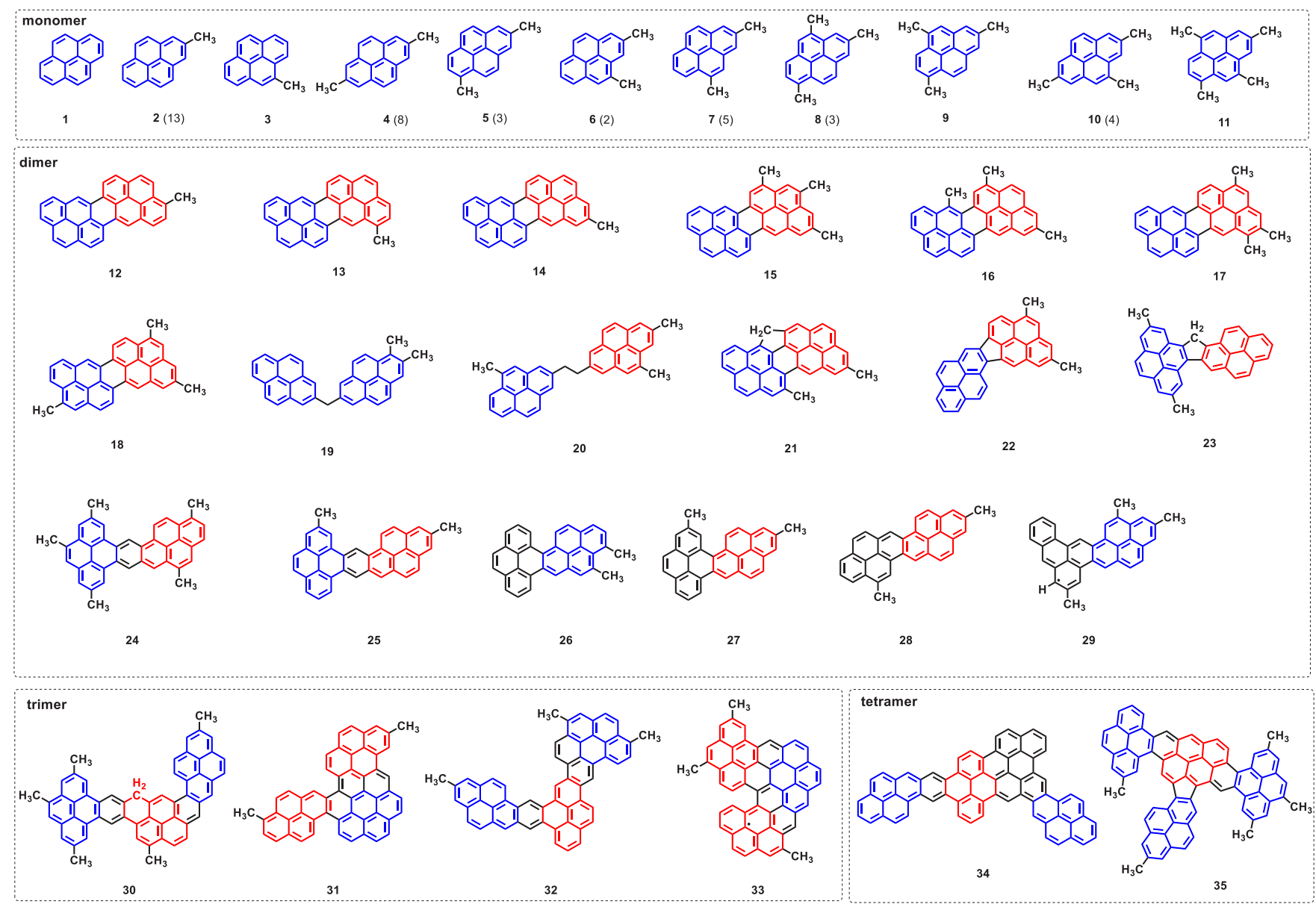

${ }^{a}$ Molecules are labeled by numbers and grouped into monomers, dimers, trimers, and tetramers. Abundance is shown as the number in parentheses if observed more than once by AFM. Different pyrene units are indicated by different colors to show the fused structures.

(indicated by dashed lines). However, it is less clear for images in panels B5, C3, and E2 (Figure 2), which might either be assigned to separate molecules with methyl groups or a single molecule connected by a covalent linker between two pyrene units (such as $\mathrm{CH}_{2}$ and $\mathrm{CH}_{2} \mathrm{CH}_{2}$ ). Despite that similar structures with such linkers have previously been imaged by $\mathrm{AFM}^{41,42}$ we simulated AFM images (Figure S7) ${ }^{62}$ of the possible chemical structures and compared them to the experimental data to identify the structures. We found that a $\mathrm{CH}_{2}$ linked structure (19) is consistent with the AFM data in panel $\mathrm{B} 5$, and a $\mathrm{CH}_{2} \mathrm{CH}_{2}$ linked structure (20) is consistent with the AFM data in panel E2. Two separate molecules with methyl groups (7 and 8) are consistent with the AFM data in panel C3.

Most AFM imaged molecules could be assigned to chemical structures (Scheme 2 and Table S1) either by comparison to model compounds or by comparison with AFM simulations. A high uncertainty was still encountered in interpreting a few AFM imaged molecules ( $a-e$ in Figure 2), and hence no chemical structures were assigned to these imaged structures. A total of 35 distinct molecules could be identified from the AFM data, with their assigned chemical structures shown in Scheme 2. These molecules comprise 11 monomers (1-11) including DMPY (4), 18 dimers (12-29), 4 trimers (30-33), and 2 tetramers $(34,35)$. While each oligomer (dimer, trimer, and tetramer) is observed only once in the AFM data, most monomers are observed multiple times. For example, molecule 2 is observed 13 times, while DMPY (4) is observed 8 times and 7 is observed 5 times. The 35 identified structures have a total of 22 unique formulas and molecular weights. This result is roughly consistent with $\sim 17$ molecular ions $(\mathrm{m} / z)$ observed by FT-ICR MS in Figure 1f. In addition, GC-MS identified only the monomers (no oligomers), and their relative abundances were reasonably consistent with AFM observations (Figures S4 and S5 and Table S1). The structures derived from the AFM data are also consistent with the NMR data, as most molecules contain only methyl groups and aromatic moieties. Very few molecular structures contain a $\mathrm{CH}_{2}$ linker $(19,21$, 23, and 30), indicating that the lack of their detection by NMR is likely caused by their low abundance. In addition, two free radical species (29 and 33) were observed, and subsequently confirmed by absorptions in electron paramagnetic resonance (EPR) spectra, indicating that the quantitative NMR results could be likely affected by these paramagnetic radical species.

These product structures characterized by AFM make it possible to deduce the thermal transformation of DMPY and their reaction mechanisms. At a higher level regardless of mechanisms, four types of reactions can be summarized related to the transformation of DMPY (Scheme 3).

First, methyl transfer is identified as a major reaction pathway by examining the resolved monomers. The observation of many isomers of methylpyrenes (1-11), including 
Scheme 3. Four Types of Reactions during the Thermal Transformation of DMPY Deduced from AFM Structures, Including Methyl Transfer (1), Direct Coupling (2), Coupling via Carbon Addition (3), and Coupling via Carbon Deletion (4)

(1) methyl transfer

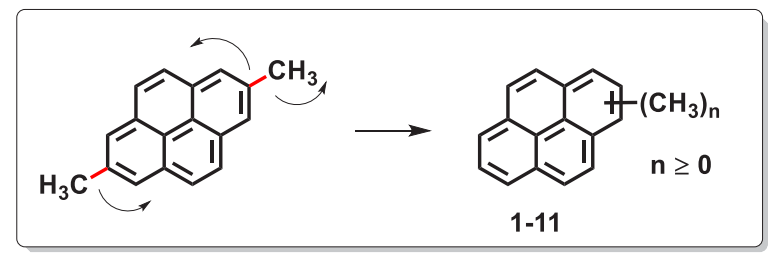

(2) direct coupling

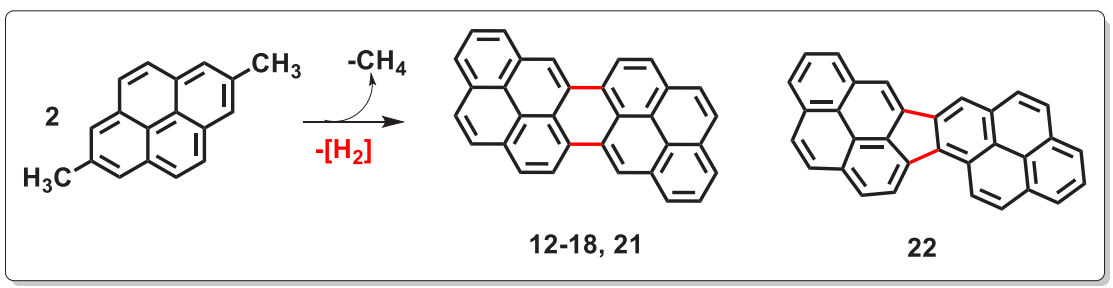

(3) coupling via carbon addition

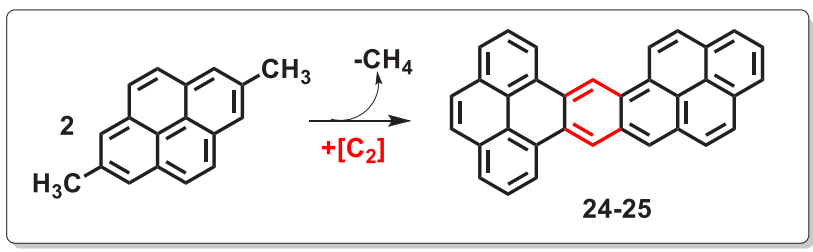

(4) coupling via carbon deletion

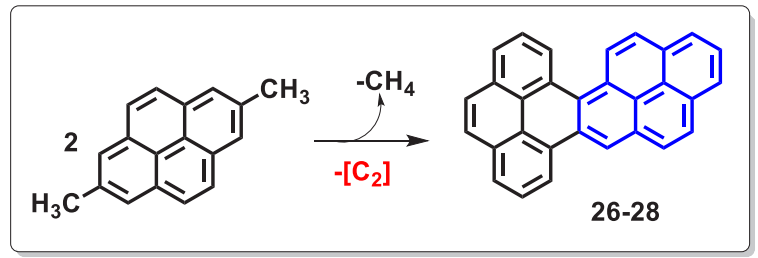

unsubstituted pyrene (1), indicates frequent methyl transfers or migrations. Substituted methyl groups are scrambled on pyrene and are different from their original 2,7-positions. Dealkylation is evident based on structures 1-3 by the loss of one or both methyls. Transfer of methyls occurs both intraand intermolecularly, evidenced by structures 8-11, which contain 3-4 methyls. Methyl transfers are evidently predominant in fused products as well.

Second, the coupling or condensation reaction is evident from dimer products. Several types of dimerization can be identified by examining their molecular structures. (a) Most of the dimer products can be considered as a direct coupling between two pyrene units via an aromatic hexagonal ring, and this accounts for about half of the dimers $(\mathbf{1 2 - 1 8}, \mathbf{2 1})$. The sites of fusion in product structures are different from the original substitution positions (ipso) of methyl groups. Direct coupling via an aromatic five-membered ring is observed in only one molecule (22), suggesting that this coupling is infrequent. Surprisingly, the anticipated predominant structure from Scheme 1, that is, coupling via a methylene linker $\left(\mathrm{CH}_{2}\right)$, is observed in only one molecule (19). Subsequent ring closure via cyclodehydrogenation is expected to occur in this structure, leading to the formation of an unconjugated five-membered ring. Hence, two other molecules (21 and 23) can be formed by following reaction pathways similar to that of 19 . Hence, the observation of three molecules suggests that this pathway indeed occurs, yet rarely. Suprisingly, a $-\mathrm{CH}_{2} \mathrm{CH}_{2}-$ linker is observed in one molecule (20). Observation of this structural manifold is unexpected, considering the thermal stability of a weak bond $(\mathrm{BDE} \approx 65 \mathrm{kcal} / \mathrm{mol}) .{ }^{47}$ Nevertheless, its formation can be rationalized by the combination of $\alpha$ radicals shown Scheme 1.

In addition to direct coupling, more complicated reactions are expected to form other fused structures. Two structures (24 and 25) are fused together by two extra carbon atoms with the formation of an aromatic ring between two pyrene units (coupling via carbon addition). This fusion is not surprising, based on migrated methyl groups and subsequent aromatization.

So far, the rationalization of reaction mechanisms assumes that the basic structure of pyrene will not be changed. This assumption is reasonable because the $\mathrm{CC}$ bonds in aromatic structures are very strong, and most literature indicates that rearrangement of aromatic structures (such as the 1,2swapping of carbon atoms in benzenoid PAHs) mostly occurs only at temperatures above $1000{ }^{\circ} \mathrm{C}$. $^{3}$ Indeed, most AFM observed structures are consistent with this assumption. However, unusual changes in the pyrene cores are found in a few identified molecules (26-28). In those, one of the two pyrene units is reduced by two carbon atoms (coupling via carbon deletion), that is, one pyrene is changed into a phenanthrene (26 and 27). This observation is quite 
surprising, considering the mild thermal condition involved in this study. Some structures (26 and 27) can be rationalized by a retro-Diels-Alder reaction with the loss of an acetylene $\left(\mathrm{C}_{2} \mathrm{H}_{2}\right)$ unit followed by a normal Diels-Alder reaction with pyrene. However, some other fused molecules (e.g., 28 and 34) cannot be satisfactorily explained. Hence, more complex reactions should be considered. Structural changes in the aromatic structures are more frequent for larger molecules such as trimers and tetramers (28-33). Overall, these observations indicate that the coupling reaction is more complicated than previously predicted (Scheme 1).

3.3. Mechanism of Methyl Transfer and Coupling Reactions. A detailed and consistent reaction mechanism can be rationalized based on the thermal transformations of DMPY and the reaction conditions employed. Methyl transfer has been discovered since the early days of coal research. ${ }^{63,64}$ Although the direct cleavage of the CC bond between methyl and pyrene shown in Scheme $4 \mathrm{a}$ provides a convenient explanation for both the methyl transfer and coupling reactions, this mechanism is very unlikely because of the breakage of a very strong $\mathrm{C}_{\text {aryl }}-\mathrm{C}_{\text {alkyl }}$ bond and the formation of very unstable $\sigma$ radicals. Indeed, previous studies suggested that such a mechanism is unlikely for temperatures below 1000 ${ }^{\circ} \mathrm{C} .{ }^{21}$

A more plausible mechanism, originally proposed by Malhotra et al. and widely accepted in the literature, ${ }^{21,64-66}$ involves the attack by hydrogen radicals at the ipso position in Scheme $4 \mathrm{~b}$. In this mechanism, the abundant $\mathrm{H}$ radicals easily produced from the initial homolytic cleavage of $\mathrm{C}-\mathrm{H}$ bonds in DMPY, would attack the ipso position of DMPY (c), and the methyl radicals are subsequently expelled due to rearomatization. Hence, subsequent alkylation reactions by methyl radicals result in methyl groups transferred in products (d).

We find that this mechanism of ipso attack by $\mathrm{H}$ atoms (IAHA) not only explains the prevalent methyl transfer reactions but also explains most of the observed fused products. As shown in Scheme $4 \mathrm{e}$, the initial $\pi$ radicals (A) produced from IAHA can react with another PAH to produce the direct coupling products. The sites of fusion are consistent with the observed fused products. Therefore, this mechanism provides a self-consistent mechanism under the reaction conditions.

It is interesting to consider the fate of the $\alpha$ radical, coproduced during the $\mathrm{H}$ radical formation (reaction $\mathrm{b}$ in Scheme 4), which was previously assumed as the key intermediate to form the predominant $\mathrm{CH}_{2}$ linked products in Scheme 1. Why would the $\alpha$ radical not follow the reaction mechanism described in Scheme 1 and Scheme 4f? The $\alpha$ radical must have been formed, as evidenced by the $\mathrm{H}$ radicals, which account for methyl transfer and coupling reactions. Our explanation is that, instead of direct alkylation (f), it isomerizes to a $\pi$ radical ( $\mathrm{B}$ in reaction $\mathrm{g}$ ), which subsequently couples with another PAH (h). This hypothesis is based on the following considerations. First, the isomerization of $\alpha$ radical to $\pi$ radical (B) might be driven by the increased delocalization, at the expense of a decrease in aromaticity. It is expected that for larger PAHs the aromatic stabilization energy is decreased and hence the $\pi$ radical (B) is preferred over the $\alpha$ radical. Second, the isomerized $\pi$ radical (B) should have a similar reactivity to the $\pi$ radical (A) from IAHA, and hence both should be able to react with $\mathrm{PAH}$ in a similar fashion. In addition, the two $\pi$ radicals (A and B) can also dimerize to form the fused products (i). Alternatively, these two $\pi$ radicals
Scheme 4. Mechanisms of Methyl Transfer and Coupling Reactions Based on This Work ${ }^{a}$

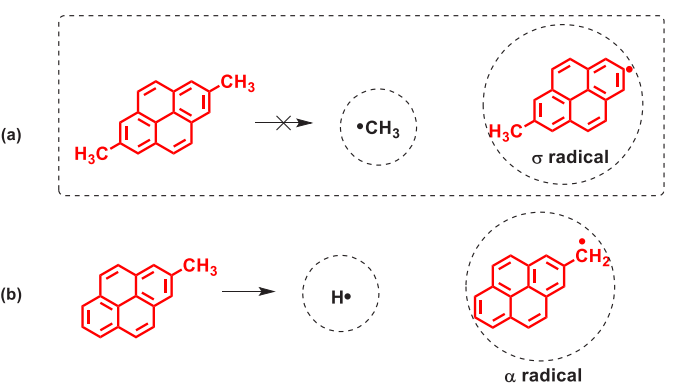

(c)

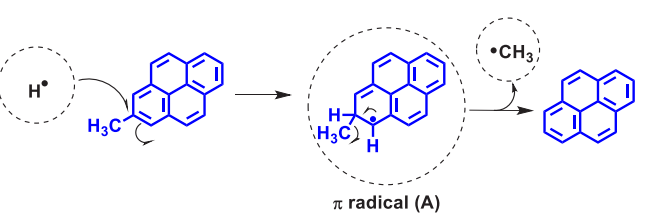

(d)

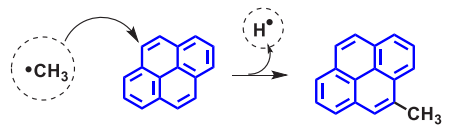

(e)

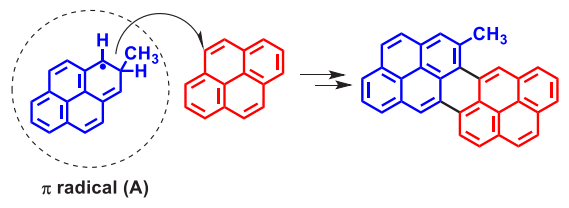

$\pi$ radical (A)

(f)

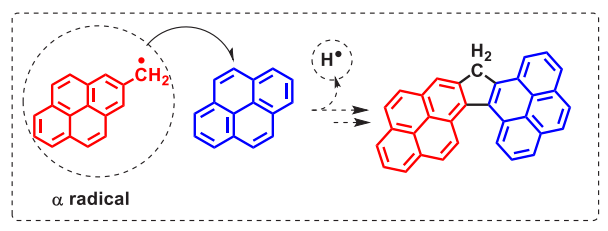

(g)

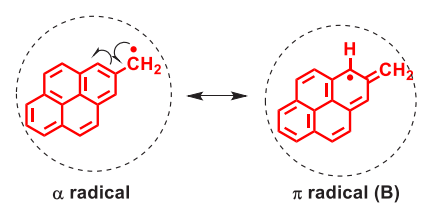

(h)

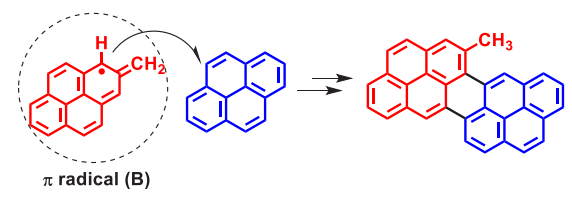

(i)

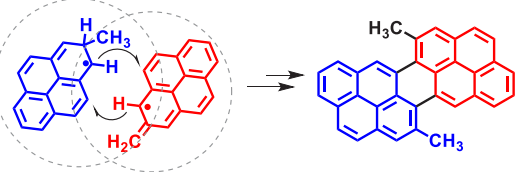

${ }^{a}$ Dashed circles indicate free radical intermediates, and dashed rectangles indicate mechanisms that are not supported or not prevalent based on the results of this study.

(A and B) can be viewed as resonance structures of the same radical. The explanation of why the $\alpha$ radicals do not follow the mechanism of Scheme 1 is that the anticipated structure with a $\mathrm{CH}_{2}$ linker would contain $\mathrm{C}-\mathrm{H}$ bonds that are weaker than those in the reactant DMPY. Hence, the formation of the expected product in reaction $\mathrm{f}$ is unlikely as $\mathrm{H}$ atoms would need to be extracted from strong $\mathrm{C}-\mathrm{H}$ bonds in DMPY. This 
is consistent with the rare observation of the $\mathrm{CH}_{2}$ linked molecules (19) by AFM.

As far as we know, this is the first report of the IAHA mechanism producing condensed $\mathrm{PAH}$ molecules. It has been widely accepted that free radicals formed from fragmentation or homolytic bond cleavage are key intermediates in thermal or hydrocracking reactions. ${ }^{21,64,65}$ In the presence of $\mathrm{H}_{2}$ or other sources of $\mathrm{H}$ atoms, stable product molecules are formed by "capping" free radicals with hydrogen atoms, and hence $\mathrm{H}$ radicals have been believed as essential in "limiting" the formation of condensed larger molecules. It is also widely believed that with a lack of $\mathrm{H}$ atoms, the fragments or free radicals would continue to react with others to produce ever larger molecules. ${ }^{21,64,65}$ However, in this study we revealed that $\mathrm{H}$ radicals also play an essential role producing radicals and creating condensed structures.

\section{CONCLUSION}

The growth of polycyclic aromatic hydrocarbons in thermally driven reactions has consequences for a wide range of practical applications. In this work, we studied the reactivity of aromatic hydrocarbons under mild thermal conditions of about 350$400{ }^{\circ} \mathrm{C}$, at which most real petroleum mixtures are known to undergo a variety of reactions to form condensed products. The early events of these reactions, especially the coupling mechanism between initial reactants, were tackled by employing model compounds and advanced characterization techniques. A comparison of dimethyl substituted pyrene with unsubstituted pyrene under identical thermal conditions revealed that methyl groups significantly reduced the thermal severity required to initiate reactions, as pyrene failed to produce any detectable products under a wide range of thermal conditions employed. A variety of products formed from 2,7dimethylpyrene (DMPY) were characterized with NMR, MS, and AFM, including monomers, dimers, and trimers. Analysis of the structures indicated that methyl transfer occurred frequently. Reaction pathways leading to the fusion of PAHs were also revealed including direct coupling between PAHs, and indirect coupling via migrated methyl groups. Furthermore, the mechanism of ipso attack by hydrogen radicals was identified for both methyl transfer and fusion of PAHs. Various mechanisms for the coupling reaction pathways were discussed, such as the ipso attack by hydrogen atoms (IAHA). These product structures revealed the complex reaction mechanisms that take place during the thermal condensation of PAHs.

\section{ASSOCIATED CONTENT}

\section{SI Supporting Information}

The Supporting Information is available free of charge at https://pubs.acs.org/doi/10.1021/acs.energyfuels.0c04016.

NMR, GC-MS, and FT-ICR MS analysis of pyrene and DMPY samples, simulated AFM images, and the summary of the AFM structure analysis (PDF)

\section{AUTHOR INFORMATION}

\section{Corresponding Authors}

Nan Yao - Princeton Institute for the Science and Technology of Materials, Princeton University, Princeton, New Jersey 08540, United States; Email: nyao@princeton.edu

Yunlong Zhang - Corporate Strategic Research, ExxonMobil Research and Engineering Company, Annandale, New Jersey
08801, United States; 다이이.org/0000-0002-3071-8625; Email: Yunlong.zhang@exxonmobil.com

\section{Authors}

Pengcheng Chen - Princeton Institute for the Science and Technology of Materials, Princeton University, Princeton, New Jersey 08540, United States

Shadi Fatayer - IBM Research-Zurich, 8803 Rüschlikon, Switzerland; 이이.org/0000-0003-4260-3208

Bruno Schuler - Empa, Swiss Federal Laboratories for Materials Science and Technology, 8600 Dübendorf, Switzerland; 이이이.org/0000-0002-9641-0340

Jordan N. Metz - Corporate Strategic Research, ExxonMobil Research and Engineering Company, Annandale, New Jersey 08801, United States

Leo Gross - IBM Research-Zurich, 8803 Rüschlikon, Switzerland; 이이이.org/0000-0002-5337-4159

Complete contact information is available at: https://pubs.acs.org/10.1021/acs.energyfuels.0c04016

\section{Notes}

The authors declare no competing financial interest.

\section{ACKNOWLEDGMENTS}

This work was supported by ExxonMobil through its membership in the Princeton E-filliates Partnership of the Andlinger Center for Energy and the Environment. This research made use of the PRISM Imaging and Analysis Center (IAC) at Princeton University, which is supported in part by Princeton Center for Complex Materials, a National Science Foundation (NSF)-MRSEC program (DMR-1420541). We also thank the European Union (Project SPRING, contract no. 863098) and the ERC grant AMSEL (682144) for support. The authors thank Anthony Mennito for collecting the FTICR MS data. Insightful discussions with Prof. Igor V. Alabugin (Florida State University) and with Prof. Arthur Winter (Iowa State University), and revision of the manuscript by Michael Siskin and Steven P. Rucker are gratefully acknowledged.

\section{REFERENCES}

(1) Qin, X.; et al. Comparison of the Effect of Graphitization on Microstructures and Properties of Polyacrylonitrile and Mesophase Pitch-Based Carbon Fibers. Carbon 2012, 50, 4459.

(2) Gherghel, L.; Kubel, C.; Lieser, G.; Rader, H.-J.; Mullen, K. Pyrolysis in the mesophase: a chemist's approach toward preparing carbon nano- and microparticles. J. Am. Chem. Soc. 2002, 124, 13130-8.

(3) Scott, L. T. Exotic Chemistry and Rational Organic Syntheses at $1000{ }^{\circ}$ C. J. Org. Chem. 2016, 81, 11535-11547.

(4) Kroto, H. W.; Heath, J. R.; O’Brien, S. C.; Curl, R. F.; Smalley, R. E. C60: Buckminsterfullerene. Nature 1985, 318, 162-163.

(5) Ramirez, A. P.; Haddon, R. C.; Zhou, O.; Fleming, R. M.; Zhang, J.; McClure, S. M.; Smalley, R. E. Magnetic Susceptibility of Molecular Carbon: Nanotubes and Fullerite. Science 1994, $265,84$.

(6) Kislov, V. V.; Islamova, N. I.; Kolker, A. M.; Lin, S. H.; Mebel, A. M. Hydrogen Abstraction Acetylene Addition and Diels-Alder Mechanisms of PAH Formation: A Detailed Study Using First Principles Calculations. J. Chem. Theory Comput. 2005, 1, 908-924.

(7) Unterreiner, B. V.; Sierka, M.; Ahlrichs, R. Reaction pathways for growth of polycyclic aromatic hydrocarbons under combustion conditions, a DFT study. Phys. Chem. Chem. Phys. 2004, 6, 43774384.

(8) Kislov, V. V.; Sadovnikov, A. I.; Mebel, A. M. Formation Mechanism of Polycyclic Aromatic Hydrocarbons beyond the Second Aromatic Ring. J. Phys. Chem. A 2013, 117, 4794-4816. 
(9) Hansen, N.; Kasper, T.; Klippenstein, S. J.; Westmoreland, P. R.; Law, M. E.; Taatjes, C. A.; Kohse-Höinghaus, K.; Wang, J.; Cool, T. A. Initial Steps of Aromatic Ring Formation in a Laminar Premixed Fuel-Rich Cyclopentene Flame†. J. Phys. Chem. A 2007, 111, 40814092.

(10) Wiehe, I. A.; Kennedy, R. J.; Dickakian, G. Fouling of Nearly Incompatible Oils. Energy Fuels 2001, 15, 1057-1058.

(11) Kondyli, A.; Schrader, W. Understanding "Fouling" in Extremely Complex Petroleum Mixtures. ACS Applied Energy Materials 2020, 3, 7251-7256.

(12) Azami, K.; Yamamoto, S.; Sanada, Y. Carbonization behavior of petroleum pitch-In situ high-temperature 13C-NMR measurements. Carbon 1993, 31, 611-615.

(13) Liu, Y.; Zhu, Y.; Liu, S.; Zhang, C. Evolution of Aromatic Clusters in Vitrinite-Rich Coal during Thermal Maturation by Using High-Resolution Transmission Electron Microscopy and Fourier Transform Infrared Measurements. Energy Fuels 2020, 34, 10781.

(14) Algelt, K. H.; Boduszynski, M. M. Composition and Analysis of Heavy Petroleum Fractions; Marcel Dekker: New York, 1994.

(15) Mullins, O. C.; Sabbah, H.; Eyssautier, J.; Pomerantz, A. E.; Barre, L.; Andrews, A. B.; Ruiz-Morales, Y.; Mostowfi, F.; McFarlane, R.; Goual, L.; Lepkowicz, R.; Cooper, T.; Orbulescu, J.; Leblanc, R. M.; Edwards, J.; Zare, R. N. Advances in Asphaltene Science and the Yen-Mullins Model. Energy Fuels 2012, 26, 3986-4003.

(16) Siskin, M.; Kelemen, S. R.; Eppig, C. P.; Brown, L. D.; Afeworki, M. Asphaltene Molecular Structure and Chemical Influences on the Morphology of Coke Produced in Delayed Coking. Energy Fuels 2006, 20, 1227-1234.

(17) Siskin, M.; Kelemen, S. R.; Gorbaty, M. L.; Ferrughelli, D. T.; Brown, L. D.; Eppig, C. P.; Kennedy, R. J. Chemical Approach to Control Morphology of Coke Produced in Delayed Coking. Energy Fuels 2006, 20, 2117-2124.

(18) Zhang, Y.; Siskin, M.; Gray, M. R.; Walters, C. C.; Rodgers, J. R. Mechanisms of Asphaltene Aggregation: Puzzles and a New Hypothesis. Energy Fuels 2020, 34, 9094-9107.

(19) Fatayer, S.; Poddar, N. B.; Quiroga, S.; Schulz, F.; Schuler, B.; Kalpathy, S. V.; Meyer, G.; Perez, D.; Guitian, E.; Pena, D.; Wornat, M. J.; Gross, L. Atomic Force Microscopy Identifying Fuel Pyrolysis Products and Directing the Synthesis of Analytical Standards. J. Am. Chem. Soc. 2018, 140, 8156-8161.

(20) Freund, H.; Matturro, M. G.; Olmstead, W. N.; Reynolds, R. P.; Upton, T. H. Anomalous side-chain cleavage in alkylaromatic thermolysis. Energy Fuels 1991, 5, 840-6.

(21) Poutsma, M. L. Free-radical thermolysis and hydrogenolysis of model hydrocarbons relevant to processing of coal. Energy Fuels 1990, 4, 113-131.

(22) Zhang, G.; Guan, T.; Qiao, J.; Wang, J.; Li, K. Free-radicalinitiated strategy aiming for pitch-based dual-doped carbon nanosheets engaged into high-energy asymmetric supercapacitors. Energy Storage Materials 2020, 26, 119-128.

(23) Chen, P.; Metz, J. N.; Mennito, A. S.; Merchant, S.; Smith, S. E.; Siskin, M.; Rucker, S. P.; Dankworth, D. C.; Kushnerick, J. D.; Yao, N.; Zhang, Y. Petroleum pitch: Exploring a 50-year structure puzzle with real-space molecular imaging. Carbon 2020, 161, 456465.

(24) Dickinson, E. M. Structural comparison of petroleum fractions using proton and 13C n.m.r. spectroscopy. Fuel 1980, 59, 290-294.

(25) Dickinson, E. M. Average structures of petroleum pitch fractions by proton/carbon-13 NMR spectroscopy. Fuel 1985, 64, 704-6.

(26) Seshadri, K. S.; Bacha, J. D.; Albaugh, E. W. Structural characterization of fractions of petroleum pitch and ethylene pyrolysis tar by proton and carbon-13 NMR spectroscopy. Fuel 1982, 61, 1095-100.

(27) Kershaw, J. R.; Black, K. J. T. Structural characterization of coal-tar and petroleum pitches. Energy Fuels 1993, 7, 420-5.

(28) Hutchenson, K. W.; Roebers, J. R.; Thies, M. C. Fractionation of petroleum pitch with supercritical toluene. J. Supercrit. Fluids 1991, 4, 7-14.
(29) Burgess, W. A.; Pittman, J. J.; Marcus, R. K.; Thies, M. C. Structural Identification of the Monomeric Constituents of Petroleum Pitch. Energy Fuels 2010, 24, 4301-4311.

(30) Cristadoro, A.; Kulkarni, S. U.; Burgess, W. A.; Cervo, E. G.; Raeder, H. J.; Muellen, K.; Bruce, D. A.; Thies, M. C. Structural characterization of the oligomeric constituents of petroleum pitches. Carbon 2009, 47, 2358-2370.

(31) Thies, M. C. Fractionation and Characterization of Carbonaceous Pitch Oligomers: Understanding the Building Blocks for Carbon Materials. Polymer Precursor-Derived Carbon; American Chemical Society: 2014; Vol. 1173, pp 85-136.

(32) Esguerra, D. F.; Hoffman, W. P.; Thies, M. C. Molecular structures of the constituents of pyrene pitches. Fuel 2014, 124, 133140.

(33) Esguerra, D. F.; Hoffman, W. P.; Thies, M. C. Fractionation of an oligomeric pyrene pitch via supercritical extraction. J. Supercrit. Fluids 2013, 79, 170-176.

(34) Greinke, R. A.; Lewis, I. C. Carbonization of naphthalene and dimethylnaphthalene. Carbon 1984, 22, 305-314.

(35) Grill, L.; Dyer, M.; Lafferentz, L.; Persson, M.; Peters, M. V.; Hecht, S. Nano-architectures by covalent assembly of molecular building blocks. Nat. Nanotechnol. 2007, 2, 687-691.

(36) Talirz, L.; Ruffieux, P.; Fasel, R. On-Surface Synthesis of Atomically Precise Graphene Nanoribbons. Adv. Mater. 2016, 28, $6222-6231$.

(37) Clair, S.; de Oteyza, D. G. Controlling a Chemical Coupling Reaction on a Surface: Tools and Strategies for On-Surface Synthesis. Chem. Rev. 2019, 119, 4717-4776.

(38) Grill, L.; Hecht, S. Covalent on-surface polymerization. Nat. Chem. 2020, 12, 115-130.

(39) Schuler, B.; Meyer, G.; Pena, D.; Mullins, O. C.; Gross, L. Unraveling the Molecular Structures of Asphaltenes by Atomic Force Microscopy. J. Am. Chem. Soc. 2015, 137, 9870-9876.

(40) Schuler, B.; Fatayer, S.; Meyer, G.; Rogel, E.; Moir, M.; Zhang, Y.; Harper, M. R.; Pomerantz, A. E.; Bake, K. D.; Witt, M.; Pena, D.; Kushnerick, J. D.; Mullins, O. C.; Ovalles, C.; van den Berg, F. G. A.; Gross, L. Heavy Oil Based Mixtures of Different Origins and Treatments Studied by Atomic Force Microscopy. Energy Fuels 2017, 31, 6856-6861.

(41) Schuler, B.; Zhang, Y.; Collazos, S.; Fatayer, S.; Meyer, G.; Perez, D.; Guitian, E.; Harper, M. R.; Kushnerick, J. D.; Pena, D.; Gross, L. Characterizing aliphatic moieties in hydrocarbons with atomic force microscopy. Chem. Sci. 2017, 8, 2315-2320.

(42) Chen, P.; Joshi, Y. V.; Metz, J. N.; Yao, N.; Zhang, Y. Conformational Analysis of Nonplanar Archipelago Structures on a $\mathrm{Cu}$ (111) Surface by Molecular Imaging. Energy Fuels 2020, 34, 12135-12141.

(43) Gross, L.; Mohn, F.; Moll, N.; Liljeroth, P.; Meyer, G. The Chemical Structure of a Molecule Resolved by Atomic Force Microscopy. Science 2009, 325, 1110-1114.

(44) Schuler, B.; Collazos, S.; Gross, L.; Meyer, G.; Perez, D.; Guitian, E.; Pena, D. From perylene to a 22-ring aromatic hydrocarbon in one-pot. Angew. Chem., Int. Ed. 2014, 53, 9004-9006.

(45) Gross, L.; Mohn, F.; Moll, N.; Schuler, B.; Criado, A.; Guitian, E.; Pena, D.; Gourdon, A.; Meyer, G. Bond-Order Discrimination by Atomic Force Microscopy. Science 2012, 337, 1326-1329.

(46) Giessibl, F. J. High-speed force sensor for force microscopy and profilometry utilizing a quartz tuning fork. Appl. Phys. Lett. 1998, 73, 3956-3958.

(47) Zhang, Y.; Schuler, B.; Fatayer, S.; Gross, L.; Harper, M. R.; Kushnerick, J. D. Understanding the Effects of Sample Preparation on the Chemical Structures of Petroleum Imaged with Noncontact Atomic Force Microscopy. Ind. Eng. Chem. Res. 2018, 57, 1593515941.

(48) Fatayer, S.; Coppola, A. I.; Schulz, F.; Walker, B. D.; Broek, T. A.; Meyer, G.; Druffel, E. R. M.; McCarthy, M.; Gross, L. Direct Visualization of Individual Aromatic Compound Structures in Low Molecular Weight Marine Dissolved Organic Carbon. Geophys. Res. Lett. 2018, 45, 5590-5598. 
(49) Gross, L.; Schuler, B.; Pavlicek, N.; Fatayer, S.; Majzik, Z.; Moll, N.; Pena, D.; Meyer, G. Atomic Force Microscopy for Molecular Structure Elucidation. Angew. Chem., Int. Ed. 2018, 57, 3888-3908.

(50) Albrecht, T. R.; Grütter, P.; Horne, D.; Rugar, D. Frequency modulation detection using high- $\mathrm{Q}$ cantilevers for enhanced force microscope sensitivity. J. Appl. Phys. 1991, 69, 668-673.

(51) Lewis, I. C. Chemistry of pitch carbonization. Fuel 1987, 66, $1527-1531$.

(52) Esguerra, D. F.; Hoffman, W. P.; Thies, M. C. Liquid crystallinity in trimer oligomers isolated from petroleum and pyrene pitches. Carbon 2014, 79, 265-273.

(53) Lamie, W. C.; Bruce, D. A.; Hoffman, W. P.; Thies, M. C. Kinetics of the catalytic polymerization of pyrene with $\mathrm{AlCl} 3$. Carbon 2018, 134, 1-8.

(54) Siskin, M.; Porcelli, J. Strong acid chemistry. I. Reactions of aromatics in the hydrogen fluoride-tantalum pentafluoride (HFTaF5) acid system. J. Am. Chem. Soc. 1974, 96, 3640-3641.

(55) Zhang, Y. Identify Similarities in Diverse Polycyclic Aromatic Hydrocarbons of Asphaltenes and Heavy Oils Revealed by Noncontact Atomic Force Microscopy: Aromaticity, Bonding, and Implications in Reactivity. In Chemistry Solutions to Challenges in the Petroleum Industry; Rahimi, P., Ovalles, C., Zhang, Y., Adams, J., Eds.; American Chemical Society: 2019.

(56) Bartels, L.; Meyer, G.; Rieder, K. H. Controlled vertical manipulation of single $\mathrm{CO}$ molecules with the scanning tunneling microscope: A route to chemical contrast. Appl. Phys. Lett. 1997, 71, $213-215$.

(57) Han, Z.; Czap, G.; Chiang, C.-1.; Xu, C.; Wagner, P. J.; Wei, X.; Zhang, Y.; Wu, R.; Ho, W. Imaging the halogen bond in selfassembled halogenbenzenes on silver. Science 2017, 358, 206-210.

(58) Zhang, J.; Chen, P.; Yuan, B.; Ji, W.; Cheng, Z.; Qiu, X. Realspace identification of intermolecular bonding with atomic force microscopy. Science 2013, 342, 611-614.

(59) Pavliček, N.; Fleury, B.; Neu, M.; Niedenführ, J.; HerranzLancho, C.; Ruben, M.; Repp, J. Atomic Force Microscopy Reveals Bistable Configurations of Dibenzo[a, h]thianthrene and their Interconversion Pathway. Phys. Rev. Lett. 2012, 108, 086101.

(60) Hämäläinen, S. K.; van der Heijden, N.; van der Lit, J.; den Hartog, S.; Liljeroth, P.; Swart, I. Intermolecular Contrast in Atomic Force Microscopy Images without Intermolecular Bonds. Phys. Rev. Lett. 2014, 113, 186102.

(61) Sweetman, A. M.; Jarvis, S. P.; Sang, H.; Lekkas, I.; Rahe, P.; Wang, Y.; Wang, J.; Champness, N. R.; Kantorovich, L.; Moriarty, P. Mapping the force field of a hydrogen-bonded assembly. Nat. Commun. 2014, 5, 3931.

(62) Hapala, P.; Kichin, G.; Wagner, C.; Tautz, F. S.; Temirov, R.; Jelinek, P. Mechanism of high-resolution STM/AFM imaging with functionalized tips. Phys. Rev. B: Condens. Matter Mater. Phys. 2014, 90, 085421-085429.

(63) Kouchi, M.; Kidena, K.; Murata, S.; Nomura, M. Methyl group migration during heat treatment of coal in the presence of polycyclic aromatic compounds. Sekitan Kagaku Kaigi Happyo Ronbunshu 1999, $36,87-90$.

(64) Kidena, K.; Bandoh, N.; Kouchi, M.; Murata, S.; Nomura, M. Methyl group migration during heat treatment of coal in the presence of polycyclic aromatic compounds. Fuel 2000, 79, 317-322.

(65) Malhotra, R.; McMillen, D. F. Relevance of cleavage of strong bonds in coal liquefaction. Energy Fuels 1993, 7, 227-233.

(66) Savage, P. E. Hydrogen-Transfer Mechanisms in 1-Dodecylpyrene Pyrolysis. Energy Fuels 1995, 9, 590-598. 